\title{
Advanced Tungsten Materials for Plasma-Facing Components of DEMO and Fusion Power Plants
}

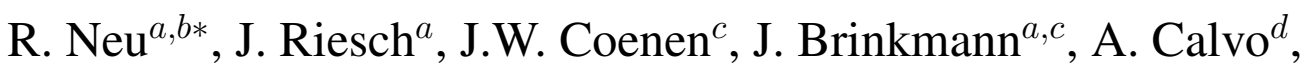 \\ S. Elgeti ${ }^{a}$, C. García-Rosales ${ }^{d}$, H. Greuner ${ }^{a}$, T. Hoeschen ${ }^{a}$, \\ G. Holzner ${ }^{a}$, F. Klein ${ }^{c}$, F. Koch ${ }^{a}$, Ch. Linsmeier ${ }^{c}$, A Litnovsky $^{c}$, \\ T. Wegener ${ }^{c}$, S. Wurster ${ }^{e, f}$, J.-H. You ${ }^{a}$ \\ ${ }^{a}$ Max-Planck-Institut für Plasmaphysik, D-85748 Garching, Germany \\ ${ }^{b}$ Fakultät für Maschinenbau, Technische Universität München, D-85748 Garching, \\ Germany \\ ${ }^{c}$ Forschungszentrum Jülich GmbH, Institut für Energie- und Klimaforschung - \\ Plasmaphysik, D-52425 Jülich, Germany \\ ${ }^{d}$ CEIT and Tecnun (University of Navarra), E-20018 San Sebastian, Spain \\ ${ }^{e}$ Department of Materials Physics, University of Leoben, Leoben, Austria \\ ${ }^{f}$ Erich Schmid Institute of Materials Science, Austrian Academy of Sciences, A-8700 \\ Leoben, Austria
}

\begin{abstract}
Tungsten is the major candidate material for the armour of plasma facing components in future fusion devices. To overcome the intrinsic brittleness of tungsten, which strongly limits its operational window, a W-fibre enhanced $\mathrm{W}$-composite material $\left(\mathrm{W}_{\mathrm{f}} / \mathrm{W}\right)$ has been developed incorporating extrinsic toughening mechanisms. Small $\mathrm{W}_{\mathrm{f}} / \mathrm{W}$ samples show a large increase in toughness. Recently, a large sample $\left(50 \times 50 \times 3 \mathrm{~mm}^{3}\right)$ with more than 2000 long fibres has been successfully produced allowing further mechanical and thermal testing. It could be shown that even in a fully embrittled state, toughening mechanisms as crack bridging by intact fibres, as well as the energy dissipation by fibre-matrix interface debonding and crack deflection are still effective. A potential problem with the use of pure $\mathrm{W}$ in a fusion reactor is the formation of radioactive and highly volatile $\mathrm{WO}_{3}$ compounds and their potential release under accidental conditions. It has been shown that the oxidation of $\mathrm{W}$ can be strongly suppressed by alloying with elements forming stable oxides.
\end{abstract}


WCr10Ti2 alloy has been produced on a technical scale and has been successfully tested in the high heat flux test facility GLADIS. Recently, W-Cr-Y alloys have been produced on a lab-scale. They seem to have even improved properties compared to the previously investigated $\mathrm{W}$ alloys.

keywords:

plasma facing components, tungsten, composite materials, (extrinsic) toughening, selfpassivating alloys

* Corresponding author address: Boltzmannstr.2 85748 Garching

*Corresponding author E-mail: Rudolf.Neu@ipp.mpg.de

Presenting author: Rudolf Neu

Presenting author e-mail: Rudolf.Neu@ipp.mpg.de

\section{Introduction}

Plasma-facing materials of future fusion power plants will face unique challenges in terms of power, particle and neutron loads [1]. Tungsten (W) is the main candidate material for the first wall as it is resilient against erosion, has the highest melting point of any available metal and shows rather benign behaviour under neutron irradiation. However, tungsten has a fairly high ductile to brittle transition temperature (DBTT) even increasing under neutron irradiation. To overcome this brittleness, mainly $\mathrm{W}$ alloying (for example [2-4]) and oxide dispersion strengthened/stabilized W materials (for example [5-7]) were investigated (see [8] and [9] for recent reviews on the $\mathrm{W}$ materials development). Another route is $\mathrm{W}$-composite material. In plasma facing components a combination of $\mathrm{W}$ with $\mathrm{Cu}$ has been proposed for tungsten laminates [10], functionally graded W/Cu layers (see for example [11,12]) and $\mathrm{W}$ fibres in a $\mathrm{Cu}$ matrix (see for example [13-15]. Specifically the laminates and the fibre reinforced composites make use of the exceptional mechanical properties of tungsten foils and fibres. Combined with the high thermal conductivity of $\mathrm{Cu}$ they yield improved thermomechanical properties at temperatures beyond the operational range of $\mathrm{CuCrZr}$. If the material is intended to be used as armour material, the maximum temperature can range beyond $1000^{\circ} \mathrm{C}$ 
which requires a further step towards composites using only tungsten. To this end tungsten-fibre reinforced tungsten-composites $\left(\mathrm{W}_{\mathrm{f}} / \mathrm{W}\right)$ has been developed incorporating extrinsic toughening mechanisms [16].

A potential problem with the use of pure $\mathrm{W}$ in a fusion reactor is the formation of radioactive and highly volatile $\mathrm{WO}_{3}$ compounds and their potential release under accidental conditions. It has been shown that the oxidation of $\mathrm{W}$ can be strongly suppressed by alloying with elements forming stable oxides as a passivating layer[17]. In the following section the basic procedure and ingredients of the production of $\mathrm{W}_{\mathrm{f}} / \mathrm{W}$ composites will be sketched. Section 3 will concentrate on the results of mechanical bending tests of fully embrittled $\mathrm{W}_{\mathrm{f}} / \mathrm{W}$ specimens and their interpretation in terms of toughening. In Sec. 4 the status of the current development of self-passivating $\mathrm{W}$-alloys will be shortly summarized and results of the latest experiments will be presented. Finally, Sec. 5 will conclude the paper and give an outlook on the planned activities which are aimed at the industrial scale production of material samples for their testing as part of plasma facing components.

\section{Tungsten fibre reenforced tungsten $(\mathbf{W} f / \mathbf{W})$}

\subsection{Fabrication of the tungsten matrix in $W_{\mathrm{f}} / W$ composites}

The very high melting point and high temperature strength both for fibre and matrix do not allow for conventional composite production routes (see examples in [18]). Furthermore it is important that the properties of fibre and interface are not degraded during the process. Chemical deposition techniques allow low processing temperatures $\left(<600^{\circ} \mathrm{C}\right)$ and a force-less fabrication, and thus the preservation of the interface and fibre integrity as well as fibre topology. In this process tungstenhexafluoride is reduced by hydrogen in a heterogeneous surface reaction and thus solid tungsten is formed. The sample prepared for the bending tests described below is produced by chemical vapour deposition (CVD) on a fibrous preform consisting of pure tungsten wire with a diameter of $150 \mu \mathrm{m}$ (similar as for the chemical infiltration experiments performed in [16]). The fibres were coated in advance by magnetron sputtering with an $\mathrm{Er}_{2} \mathrm{O}_{3}$ interface layer with a thickness of $1 \mu \mathrm{m}$ in order to provide a stable interface towards the matrix (see [19] for details on the process). Laterally, the fibres are separated by approximately $100 \mu \mathrm{m}$ by means of a mechanical clamping system. The sample was built successively depositing tung- 
sten on each layer adding another fibre layer when the latter one was completely coated. By this procedure a vertical distance of the fibre planes slightly above 100 $\mu \mathrm{m}$ is achieved. In total 10 fibre planes with 220 fibres each were deposited. The sample has a size of about $25 \mathrm{~cm}^{2}$ and a volume of $10.7 \mathrm{~cm}^{3}$. Its density reaches 93-96\% (deduced from image evaluation) and a fibre volume fraction of about 0.3 has been achieved in this way. Fig. 1 shows the sample after production and its metallographical cross section (right).
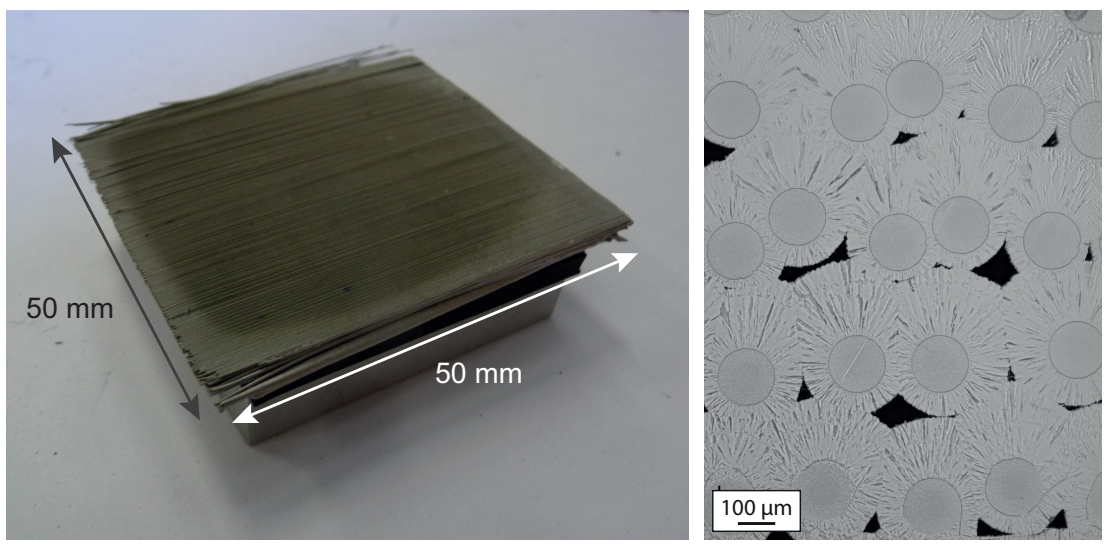

Fig. 1. Photo of the as produced $\mathrm{W}_{\mathrm{f}} / \mathrm{W}$ sample (left) and its metallographical cross section (right (optical microscopy)) showing the fibres and the radial crystal growth of the matrix. The dark areas in the cross section show the pores resulting from the CVD process.

\subsection{Mechanical properties of $W$-wire used as fibre in $W f / W$ composites}

A key benefit of $\mathrm{W}_{\mathrm{f}} / \mathrm{W}$ under cyclic high heat loads are the exceptional properties of the tungsten wires used as fibres: Pure as well as potassium doped (K-doped) tungsten wires show exceptional ductility and strength in contrast to conventional bulk tungsten being brittle at room temperature. These are ideal properties facilitating the toughening in $\mathrm{W}_{\mathrm{f}} / \mathrm{W}$ as the high strength is important for the bridging effect and ductile deformation allows the dissipation of substantial amount of energy [20]. Pure tungsten and potassium doped wires with a diameter of $150 \mu \mathrm{m}$ supplied by OSRAM GmbH have been investigated by means of tensile tests in $[21,22]$. The pure $\mathrm{W}$ wires were tested in the as-fabricated state and after annealing for 30 minutes at $1273 \mathrm{~K}$ and $1900 \mathrm{~K}$. Whereas the as-fabricated and the low heat treated fibres showed ductile behaviour and a strength of more than $2900 \mathrm{MPa}$ and $1900 \mathrm{MPa}$, respectively, the high temperature heat treated fibres failed in a brittle manner with a mean fracture strength of approximately $900 \mathrm{MPa}$, but revealing a large scatter. The potassium doped wires were annealed up to $2573 \mathrm{~K}$. Only at this 
very high annealing temperatures a strong (secondary) grain growth was observed leading to a brittle failure. For annealing temperatures up to $2173 \mathrm{~K}$ the potassium doped wires showed a ductile behaviour with strengths reaching from $2720 \mathrm{MPa}$ (as fabricated state) to $1970 \mathrm{MPa}$ (annealed at $2173 \mathrm{~K}$ ). Details on the experiment, specifically concerning the differences in the recrystallisation between the pure and the K-doped wires can be found in [22]. Similar to pure tungsten wires the embrittlement of the K-doped wires is correlated with the loss of the fine elongated grain structure. As the K-doped wire does not lose its good mechanical properties and in particular its ductile behaviour up to very high temperature the application temperature of $\mathrm{W}_{\mathrm{f}} / \mathrm{W}$ might be considerably increased if doped wires are used.

\section{Bending tests on embrittled tungsten-fibre reinforced composite}

As discussed above a key mechanism for the toughening in $\mathrm{W}_{\mathrm{f}} / \mathrm{W}$ is the ductile deformation of the fibres [20]. However, in tests with single fibre samples it could also be shown that $\mathrm{W}_{\mathrm{f}} / \mathrm{W}$ features toughness even after full embrittlement of the fibres mainly by fibre bridging and pull-out respectively [23] in agreement with the extrinsic toughening mechanisms of brittle materials described in literature [24,25]. In order to check the extrapolation from single fibre probes to samples containing several fibres bending tests on embrittled bulk $\mathrm{W}_{\mathrm{f}} / \mathrm{W}$ were performed. An in-situ surface observation by a scanning electron microscope (SEM) and dedicated surface preparation allow the observation of crack propagation and potential stopping. The testing conditions were similar to the ones done on as produced samples described in [16]. For these tests still the pure $\mathrm{W}$ wires were used as fibres because they allow the investigation of full embrittlement as a test for operationally induced effects with less experimental efforts involved.

\subsection{Sample preparation}

The test sample is cut according ASTM E399 [26] (see Fig. 2) from the the sample produced by chemical vapour deposition (CVD) as decribed above (see Sec. 2.1). In order to produce $\mathrm{W}_{\mathrm{f}} / \mathrm{W}$ with fully brittle components it is necessary to embrittle the fibres as the matrix produced by CVD behaves brittle [27] already without any treatment. Pure tungsten fibres (as used for the production of the sample) are embrittled when heated above the recrystallization temperature (see above 
and $[21,22])$, hence the tested sample was embrittled by heating it at $2000 \mathrm{~K}$ for $30 \mathrm{~min}$. Details of the process are given in [28]. A careful surface preparation is required to allow the observation of the crack propagation. A combination of a mechanical (SiC grinding paper and diamond suspension) and a mechanical-chemical (Logitech SF1 "Syton") procedure is used (details in [29]). The sample is prepared in such a way that the first layer of fibres is cut in half. This allows the observation of the interaction of the crack with the first fibre layer in the surface. This is shown in Fig. 2, where the sample is depicted schematically with a micrograph of the central region overlayed. The sample is notched to concentrate the stress at the notch tip and to create a well-defined crack initiation point. As a sharper crack lowers the load needed for crack initiation [30], a three-step notching procedure with decreasing notch radii as described in [16] is used. The overall resulting notch depth is $a=1200 \mu \mathrm{m}$.

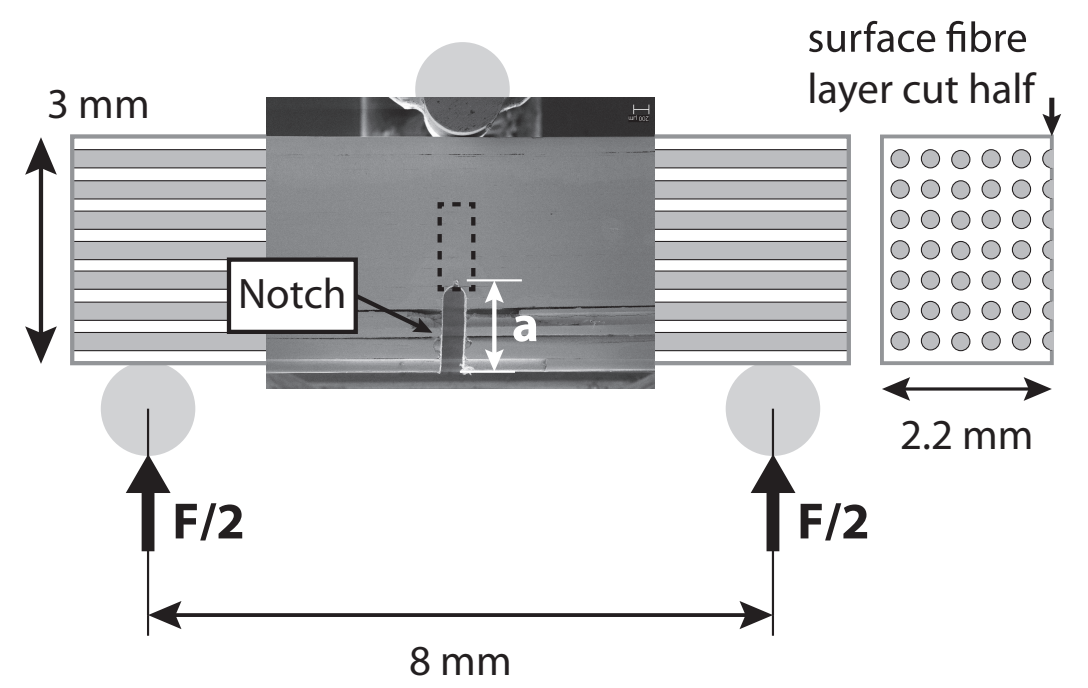

Fig. 2. Micrograph of the embrittled $\mathrm{W}_{\mathrm{f}} / \mathrm{W}$ sample and schematic drawing of 3-point bending setup. The sample is polished in a way that the surface fibre layer is cut half. The dashed box indicates the area where crack propagation has been observed.

\subsection{Bending tests with in-situ surface observation by a scanning electron micro- scope}

After the unit is installed inside the SEM, the sample is placed into the bending sample holder. The surface of the sample is orientated in a way that the load input is from top and bottom of the sample (Fig. 2). The sample is loaded in a displacementcontrolled manner while the crack tip (respectively the notch tip) is observed in a 
fast scanning mode to capture any changes at the crack tip immediately. In parallel the force measurement unit was monitored for crack propagation indicated by small load drops. For the acquisition of high quality pictures the displacement is stopped when a defined load or displacement is reached or when a sudden change at the surface or a load drop (e.g. crack propagation) is observed. Since the displacement is kept constant during this time a slight unloading of the sample may take place due to relaxations. The bending test is therefore conducted stepwise. More details on the experimental procedure are given in [16].

\subsection{Results and discussion}

The load-displacement curve of the bending test on the multi-fibre $\mathrm{W}_{\mathrm{f}} / \mathrm{W}$ sample is shown in Fig. 3 and the different phases of the test are denoted by Roman and Arabic numerals. After mechanical setup, the load increases linearly (part I). At a load of $158 \mathrm{~N}$, crack initiation in the matrix is observed at the surface (step 1 in Fig. 3 ). The crack bypasses the first fibre and is stopped between fibre 1 and 2 . The crack initiation is accompanied by a load drop of $3 \mathrm{~N}$. With on-going loading, stable crack propagation is observed, accompanied by almost linearly increasing load up to 198 $\mathrm{N}$ (part II). A load plateau is observed at $180 \mathrm{~N}$ accompanied by a simultaneous crack propagation towards the second fibre (Fig. 3, step 2). The crack is stopped at this fibre. At further loading the crack is widened but no further propagation is observed at the surface (Fig. 3,step 3). A massive load drop occurs after reaching the maximum load of $198 \mathrm{~N}$. With this load drop the sample fails completely.

The fracture toughness $K$ is determined according to ASTM E399 (equation A.3.1 and A3.2 in [26], see [16]). For the evaluation of $K$ throughout the experiment, i.e. the determination of an $\mathrm{R}$ curve, the actual crack length must be known, but in an inhomogeneous composite material such as $\mathrm{W}_{\mathrm{f}} / \mathrm{W}$ the determination of this length using only a surface observation is not possible [31]. Therefore the length of the notch, is used for a conservative estimation of $\mathrm{K}$. As the true crack length is clearly longer and even increases during the test, the true value of $\mathrm{K}$ should be even higher. The fracture toughness of the matrix (crack initiation) is $7 \mathrm{MPa} \mathrm{m} \mathrm{m}^{0.5}$ and the maximum fracture toughness is $9 \mathrm{MPa} \mathrm{m}^{0.5}$.

At room temperature, CVD tungsten typically fails in a brittle manner with a mixture of cleavage fracture and grain boundary fracture [27]. Tungsten fibres show brittle failure when heat treated above recrystallisation temperature [21]. In con- 

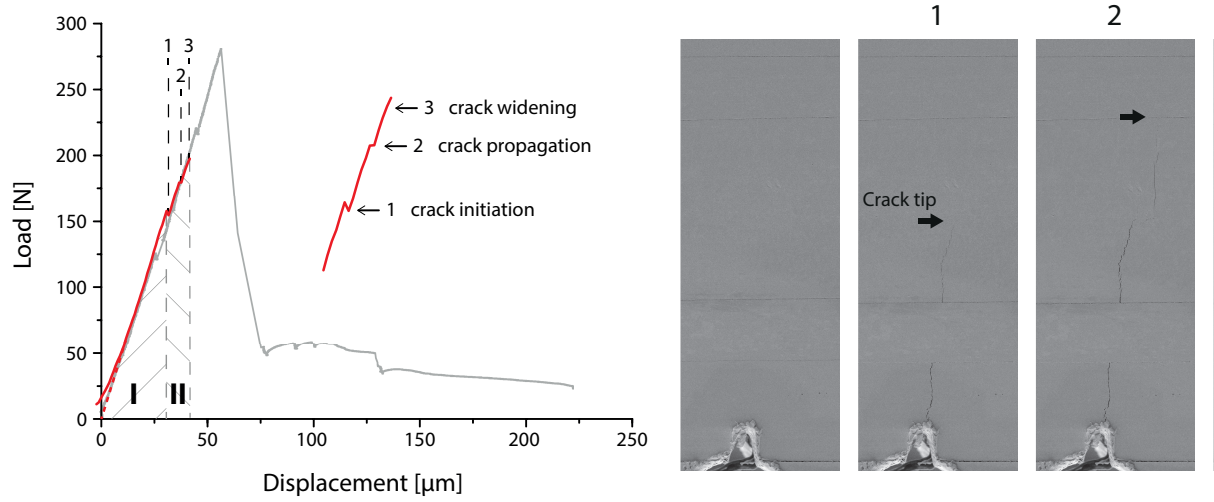

3

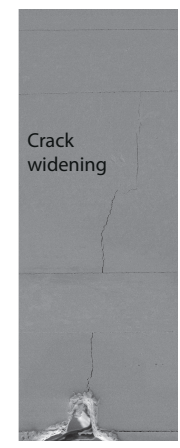

Fig. 3. Force-displacement curve of the bending test on an embrittled multi-fibre $\mathrm{W}_{\mathrm{f}} / \mathrm{W}$ sample. The dashed lines indicate a displacement stop, accompanied by a detailed surface observation. The curve was adopted and extrapolated (dotted line) in a way that the elastic line crosses the origin. Two different parts of the loading are identified with I and II. On the right micrographs of the unloaded sample (no number) and of the indicated displacement steps (1-3) are shown (observation area is indicated by dashed box in Fig. 2). Micrograph 1 shows a straight crack bypassing the first fibre. In 2 the crack propagates towards fibre 2 and is stopped there. In 3 the crack is widened.

trast the bending test reveals that $\mathrm{W}_{\mathrm{f}} / \mathrm{W}$ even when embrittled shows controlled, i.e stable, crack propagation and a rising load-bearing capacity. The crack bridging by intact fibres could be observed for the surface layer. The stress intensity for the first visible crack initiation is in a typical range for undeformed (recrystallized, sintered) tungsten materials [32]. However, in this test the load increases with increasing stable crack propagation, leading to a increase in measured toughness. This behaviour is typical for a composite material with extrinsic toughening mechanisms [33] and was already observed for as fabricated bulk $\mathrm{W}_{\mathrm{f}} / \mathrm{W}[16]$. Only the first layer of fibres is visible on the specimen's surface and only mechanisms acting in this layer are visible. Therefore a quantitative evalution of the contribution of each mechanism is not possible, however, the observed toughening effect, e.g. the crack stopping within the matrix, indicates that these mechanisms are also active within the sample. The sample shows a severe load drop accompanied by a full fracture rather than a controlled failure and a gentle slope in the load displacement curve reported 
being typical for extrinsic toughened materials [18]. This is an indication that the contribution of fibre pull-out is limited which was reported for single-fibre $\mathrm{W}_{\mathrm{f}} / \mathrm{W}$ model systems in bending tests before [23]. The main contribution to the toughening is therefore probably by elastic fibre bridging. Due to the restricted fracture strain in embrittled fibres the bridging range is restricted. Therefore only small crack opening is possible which was also observed here. An examination of the fracture surface will shed more light into the role of the respective mechanism. The crack bridging by intact fibres, as well as the energy dissipation by fibre-matrix interface debonding and crack deflection at these interfaces, have also been reported for single fibre composites [20,23]. Similarly, the rising load bearing capacity after crack initiation has been observed for as fabricated samples [16]. However in the latter case the maximum load is higher and no catastrophic failure occurs after the first severe load drop. The main reason for this is probably that in this case the ductile deformation of the fibres is the main toughening mechanism, which is more effective and robust under bending load [23]. In addition the different fabrication processes (dual step chemical infiltration (in the case of [16]) rather than the layered process used here) have a noticeable impact on the matrix microstructure and thereby on the crack formation and propagation. A quantitative comparison of the results is therefore difficult and additional tests for both states are planned to quantify the similarities and differences.

In summary, the toughening effect increases the load-bearing capability even with crack propagation before a pronounced macroscopic effect occurs. Extrapolating the this behaviour to a real structure implies that restricted cracks (size or location) are not necessarily catastrophic as normally in brittle materials.

\section{Development of self-passivating tungsten alloys}

A potential problem with the use of pure $\mathrm{W}$ as first wall material in a fusion reactor is the formation of radioactive and highly volatile $\mathrm{WO}_{3}$ compounds and their potential release in case of a loss of coolant accident (LOCA) with additional air ingress. In order to suppress the release of $\mathrm{W}$ oxides the use of tungsten-based alloys containing vitrifying components seems to be feasible. Enhanced erosion of light elements during normal reactor operation is not expected to be of concern. During operation plasma ions erode the light constituents of the alloy (preferential sputtering [34]), leaving behind a thin depleted zone with only tungsten remain- 
ing. Subsequently, the tungsten layer suppresses further erosion, hence utilizing the beneficial properties of tungsten. In case of a loss-of-coolant and air or water ingress the tungsten layer oxides releasing a minimum amount of $\mathrm{WO}_{3}$ and then passivating the alloy due to the content of elements being enriched at the surface and producing temperature stable oxides (see Fig. 4).

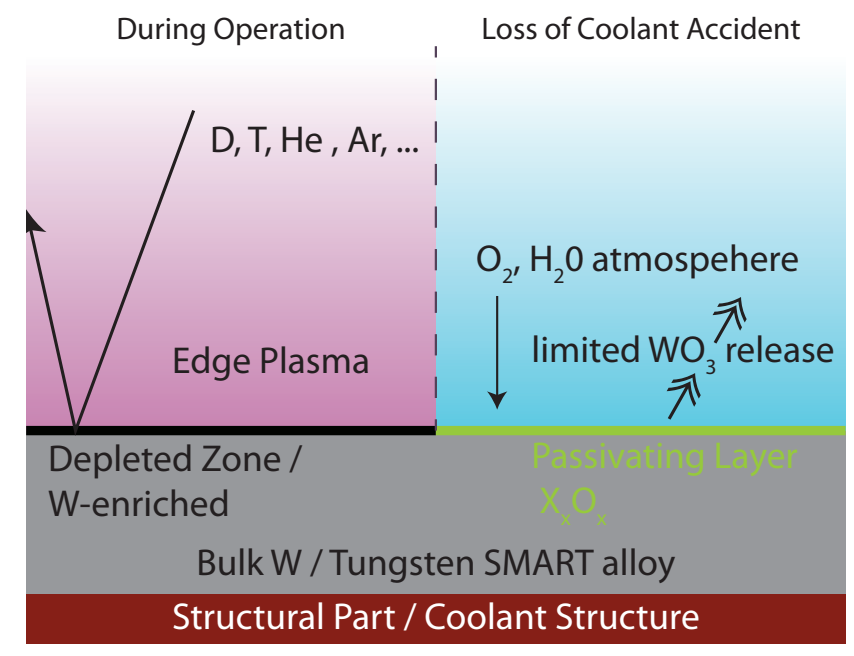

Fig. 4. Schematic behaviour of self-passivating $\mathrm{W}$ alloys.

Left side: Normal operation (at $\approx 600^{\circ}$ wall temperature): formation of a $\mathrm{W}$ surface by depletion of alloying elements through preferential sputtering.

Right side: Accident conditions (up to $\approx 1200^{\circ} \mathrm{K}$, oxygen atmosphere): formation of a protective layer against further $\mathrm{W}$ oxidation and release.

\subsection{Thin layers as model systems}

In order to allow an efficient test of the basic oxidation behaviour of different $\mathrm{W}$ alloy systems screening was performed on thin films produced by magnetron sputtering. The setup consisted of up to five magnetrons and pure elements were used as sputter targets. The composition of the individual samples was adjusted by variation of the discharge power of each magnetron. As substrates quartz and sapphire were used. The advantage of this procedure stems from the fact that alloys of multiple elements with any composition can be produced. Moreover a nano-dispersive distribution can be achieved, however at the cost that only layers wit a few microns can be deposited (see [17]). Many ternary systems have been investigated as for example W-Cr-Ti, W-Ta-Ti, W-Ta-Zr, W-Ta-Hf, W-Hf-Ti, W-Cr-Zr, W-Zr-Ti amongst which the system $\mathrm{W}-\mathrm{Cr}-\mathrm{Ti}$ ( $\geq 10$ wt.\% Cr, 2 wt.\% Ti)showed the lowest oxidation rate. 
Very recent studies demonstrated significant advantages of W-Cr-Y self-passivating alloys [35]. For production of these alloys, three-electrode configuration of the PREVAC magnetron facility was used. The tungsten target was operated at DC mode with applied voltage of $-420 \mathrm{~V}$ to $-340 \mathrm{~V}$ and the power of $420-500 \mathrm{~W}$. Similarly, the chromium target was operated in DC mode with the voltage ranging from $-310 \mathrm{~V}$ to $-240 \mathrm{~V}$ and the corresponding power of 150-270 W. The Yttrium target was operated in RF mode with applied power of 40-170 W and voltage of 105-270 V. The duration of the exposure was in the range of 60-130 minutes. The substrates were not actively heated during exposure. The grown films had homogenous nano-crystalline structure with the tungsten grains ranging $100 \mathrm{~nm}-500 \mathrm{~nm}$ as detected with electron-beam analyses. X-Ray diffraction (XRD) measurements performed on the films, provide clear peaks of tungsten and chromium outlining the purity of these elements in the produced alloy and the absence of oxidation during the film preparation. Due to its low amount, yttrium was not detectable. Experiments performed on quartz and sapphire substrates do not reveal noticeable influence of substrate material on grown film.

The addition of even a small amount of yttrium in the alloy is expected to increase the stability and smoothness of chromium oxide in the alloy system. A scan of the elemental composition of the alloys was performed and as the result of these studies, the self-passivating alloy containing $89.7 \mathrm{wt} \%$ of $\mathrm{W}, 10 \mathrm{wt} . \%$ of $\mathrm{Cr}$ and 0.3 wt.\% of $\mathrm{Y}$ was developed and obtained in the lab scale. As for direct comparative oxidation test of the candidate alloys $\mathrm{W}-\mathrm{Cr}, \mathrm{W}-\mathrm{Cr}-\mathrm{Ti}$ and $\mathrm{W}-\mathrm{Cr}-\mathrm{Y}$ alloys were tested under identical oxidation conditions. W-Cr-Y achieves superior suppression of oxidation in comparison with $\mathrm{W}-\mathrm{Cr}$ and $\mathrm{W}-\mathrm{Cr}-\mathrm{Ti}$ alloy systems. The parabolic oxidation constant of the Y-containing system at $1000^{\circ} \mathrm{C} k_{p(W-C r-Y)}=6.5 \cdot 10^{-6}$ $\mathrm{mg}^{2} \mathrm{~cm}^{-4} \mathrm{~s}^{-1}$ is much smaller than that of W-Cr $k_{p(W-C r)}=6.7 \cdot 10^{-5} \mathrm{mg}^{2} \mathrm{~cm}^{-4} \mathrm{~s}^{-1}$ ) and of W-Cr-Ti, $\left.k_{p(W-C r-T i)}=2.3 \cdot 10^{-5} \mathrm{mg}^{2} \mathrm{~cm}^{-4} \mathrm{~s}^{-1}\right)$.

\subsection{Production of bulk $W$ alloy materials}

Although the thin W-alloy layers allow an efficient selection of potential selfpassivating systems, production of larger/thicker samples and finally of amounts on technical scale is indispensable in order to allow a full characterisation of the oxidation process (also taking into account diffusion from the bulk) as well as thermomechanical tests. Laboratory size samples $\left(\varnothing 15 \times 30 \mathrm{~mm}^{3}\right)$ of $\mathrm{WCr} 10 \mathrm{Ti} 2$ have been produced by encapsulation and hipping at $1200^{\circ} \mathrm{C}(150 \mathrm{MPa}, 1 \mathrm{~h})$ resulting in 
$100 \%$ dense homogenous material with an average grain size of 100-150 nm [36] (see Fig. 5).

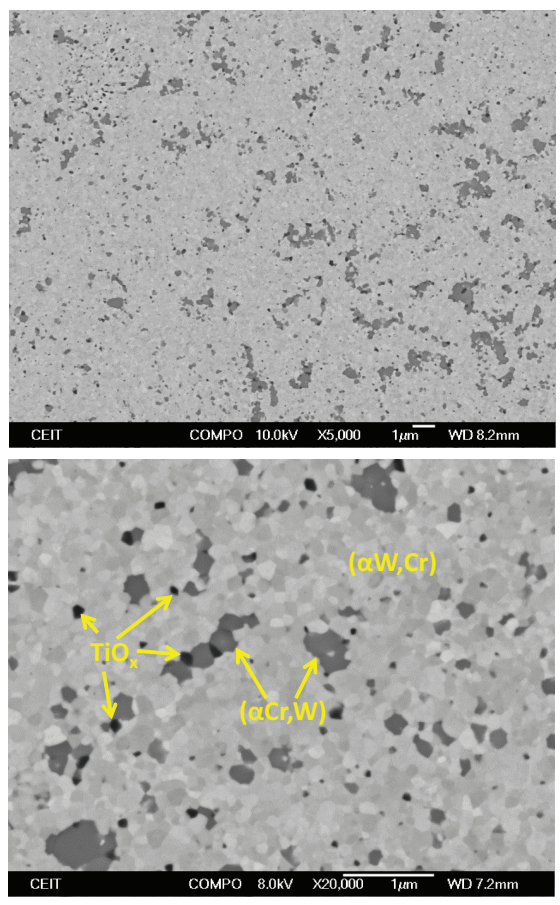

Fig. 5. SEM micrographs of WCr10Ti2 produced by encapsulation and hipping at $1200^{\circ} \mathrm{C}$ at $150 \mathrm{MPa}$ for $1 \mathrm{~h}$.

Additional thermal treatment at $1600^{\circ} \mathrm{C}$ leads to an increased grain size $(\approx 1 \mu \mathrm{m})$, a decrease of hardness as well as a decrease of the Cr-rich phase. Similar observations were made after first successful irradiation tests at the high heat flux test facility GLADIS [37] $\left(P / A=2 \mathrm{MWm}^{-2}, \Delta t=2 \mathrm{~s}, T_{\text {surf }}(\right.$ calc $) \approx 1000^{\circ} \mathrm{C}, 30$ pulses): The $\mathrm{Cr}$ content was reduced on the first few $\mathrm{nm}$ resulting in an enrichment of $\mathrm{W}$ (more than expected from preferential sputtering), as deduced from SEM investigation using a focussed ion beam for cross-sectioning. Besides that no structural damage of the sample was observed.

\subsection{Experiments and discussion}

The oxidation behaviour of the bulk WCr10Ti2 samples was tested under 'accidental-like' conditions: The samples were heated up to $600^{\circ} \mathrm{C}$ and exposed to synthetic air $\left(\mathrm{Ar}+\mathrm{O}_{2}\right)$. Subsequently the temperature was slowly ramped up to $1000^{\circ} \mathrm{C}(16.7$ h) and the weight increase (due to oxidation) was measured. At $1000^{\circ} \mathrm{C}$ the temperature was held for another 4 hours toggling the oxygen supply on and off twice. 
The sample shows a rapid increase of its weight starting from about $900^{\circ} \mathrm{C}$ and a parabolic behaviour in the isothermal segments (at $1000^{\circ} \mathrm{C}$ ) (see Fig. 6). During the phases with no oxygen injection no mass loss was detected, which means that the evaporation of tungsten oxides is below the sensitivity of the measurement.

Motivated by the encouraging results with W-Cr-Y layers, the powder metal-

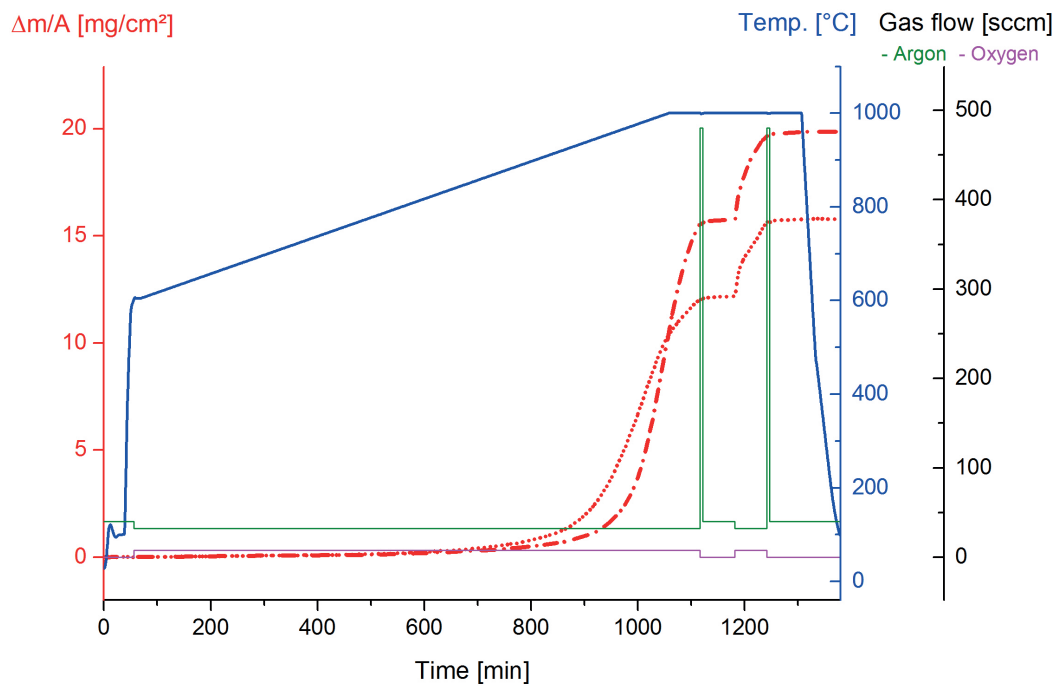

Fig. 6. Mass change during the oxidation of WCr10Ti2 under accidental-like' conditions. The trajectory of the preprogrammed temperature ramp is given in blue, those of the argon and oxygen flow rate in green and magenta, respectively. The large 'spikes' in the Ar flow were programmed for a rapid flushing of the residual oxygen gas. The red curves give the mass change for the as fabricated alloy (dash-dotted line) and for $\mathrm{W}$-alloy previously at $1600^{\circ}$ heat treated one (dotted line). Further explanation please see text.

lurgical production of $\mathrm{W}-\mathrm{Cr}-\mathrm{Y}$ has just started. The industrial fabrication of the WCr10Ti2 alloy is ongoing and two samples with masses above $1 \mathrm{~kg}$ have been already produced. Details on their microstructure and the results of first oxidation tests will be presented elsewhere [38].

\section{Summary and Outlook}

Tungsten is the main candidate material for the first wall as it is resilient against erosion and has the highest melting point of any available metal. However, it has a fairly high ductile to brittle transition temperature even increasing under neutron ir- 
radiation. Furthermore its use as first wall armour bares the risk of potential release of highly volatile (radioactive) $\mathrm{WO}_{3}$ compounds in the case of a loss of coolant accident (LOCA) with additional air ingress.

In order to overcome the intrinsic brittleness of $\mathrm{W}$, a possible concept is its reenforcement by $\mathrm{W}$ fibres. The proof of principle has been achieved with $\mathrm{W}_{\mathrm{f}} / \mathrm{W}$ model systems in the as-produced and embrittled state $[20,23]$ and with as fabricated bulk samples [16]. In this work, the first mechanical experiment on embrittled tungsten fibre-reinforced tungsten composites containing multiple fibres has been presented. An active extrinsic toughening effect is demonstrated in a qualitative and quantitative in-situ analysis. Controlled, i.e. stable, crack propagation and a rising load-bearing capacity has been shown. Interface debonding and crack bridging are directly observed. A detailed examination of the fracture surface together with an analytical description of the experiment will be presented in a succeeding paper. The experimental observation proofs that the toughening in $\mathrm{W}_{\mathrm{f}} / \mathrm{W}$ is still effective after embrittlement, which is important for fusion applications in view of accidental thermal overload and the embrittlement through neutron irradiation.

The recent installation of a CVD device at the Forschungszentrum Jülich will allow a strong optimisation of the deposition process parameters. The investigations will aim at low porosity samples with improved interfaces with the final goal of the production of an actively cooled component with $\mathrm{W}_{\mathrm{f}} / \mathrm{W}$ as plasma facing material. This will be achieved by the use of textile techniques for the production of tungsten fibre fabrics, which could be demonstrated recently with the proper parameters for the fibre arrangement. Together with a tool to position the fibre fabrics insitu without venting the recipient larger sample thicknesses necessary for the production of PFC mock-ups should become available soon [39]. Further optimisation of the properties of $\mathrm{W}_{\mathrm{f}} / \mathrm{W}$ can be achieved by optimizing the fibre coating in order to control the interface debonding. As the potassium doped W-wires do not lose their good mechanical properties and in particular its ductile behaviour up to very high temperature [22] the application temperature of $\mathrm{W}_{\mathrm{f}} / \mathrm{W}$ might be strongly increased making use of the ductile behaviour of the doped wire. Furthermore it could open the powder metallurgical production route for $\mathrm{W}_{\mathrm{f}} / \mathrm{W}$ composites [40] since the fabrication temperature could be significantly increased.

The development of self-passivating $\mathrm{W}$-alloys has already progressed to the production of first samples on an industrial scale. Rigorous investigations of their oxidation behavior and testing under high heat flux and plasma loads are either progressing or are under preparation. The material can be considered for first wall components with surface temperatures below $\approx 1000^{\circ}$ especially when combined 
with the strengthening properties of the $\mathrm{W}_{\mathrm{f}} / \mathrm{W}$ composite which might become possible if its powder mechanical production route becomes available.

In addition to the above described investigations important aspects of plasma material interaction, specifically the behaviour and retention of hydrogen in the material have to assessed in an early stage in order to satisfy the integrated approach necessary for the material's application in a future fusion reactor [1].

\section{Acknowledgements}

The authors want to acknowledge support by Osram GmbH, Schwabmünchen, Germany for providing the tungsten wire, Archer Technicoat Ltd, High Wycombe, UK for assistance in the CVD production and Mrs G. Matern for the thorough metallographical preparation. This work has been carried out within the framework of the EUROfusion Consortium and has received funding from the Euratom research and training programme 2014-2018 under grant agreement No 633053. The views and opinions expressed herein do not necessarily reflect those of the European Commission 


\section{References}

[1] J. Coenen, et al., Materials for DEMO and reactor applications-Boundary condition and new concepts, in presented at the 15th Int. Conf. on Plasma-Facing Materials and Components for Fusion Applications (PFMC15), Aix-en-Provence, France, accepted for publication in Physica Scripta, 2015.

[2] S. Wurster, et al., Int. Journal of Refractory Metals and Hard Materials 28, 692697 (2010).

[3] J. Hohe and P. Gumbsch, Journal of Nuclear Materials 400, 218 (2010).

[4] S. Wurster, et al., Journal of Nuclear Materials 413, 166 (2011).

[5] A. Muñoz, et al., Journal of Nuclear Materials 417, 508 (2011).

[6] M. Aguirre, et al., Journal of Nuclear Materials 404, 203 (2010).

[7] L. Veleva, et al., International Journal of Refractory Metals and Hard Materials 50, 210 (2015).

[8] S. Wurster, et al., Journal of Nuclear Materials 442, S181 (2013).

[9] M. Rieth, et al., Journal of Nuclear Materials 432, 482 (2013).

[10] J. Reiser, et al., Advanced Engineering Materials 17, 491 (2015).

[11] J. Song, et al., Journal of Nuclear Materials 442, S208 (2013).

[12] A. Zivelonghi and J.-H. You, Computational Materials Science 84, 318 (2014).

[13] A. Herrmann, et al., Journal of Nuclear Materials 386 - 388, 453 (2009).

[14] L. Duan, et al., International Journal of Refractory Metals and Hard Materials 46, 96 (2014).

[15] S. Liang, et al., Materials Characterization 110, 33 (2015).

[16] J. Riesch, et al., Physica Scripta 2014, 014031 (2014).

[17] F. Koch, et al., Physica Scripta 2011, 014019 (2011).

[18] K. Chawla, in Ceramic Matrix Composites, London, UK, 1993, Chapmann and Hall.

[19] J. Du, et al., Composites Science and Technology 70, 1482 (2010).

[20] J. Riesch, et al., Acta Materialia 61, 7060 (2013). 
[21] P. Zhao, et al., Microstructure, mechanical behavior and fracture of pure tungsten wires after different heat treatments, in submitted to Int. Jour. of Refr. Metals and Hard Materials, 2015.

[22] J. Riesch, et al., Development of tungsten fibre-reinforced tungsten composites towards their use in DEMO Potassium doped tungsten wire, in presented at the 15th Int. Conf. on Plasma-Facing Materials and Components for Fusion Applications (PFMC15), Aix-en-Provence, France, accepted for publication in Physica Scripta, 2015.

[23] J. Riesch, et al., Crack bridging in as-produced and embrittled tungsten single fibre reinforced tungsten composites shown by a novel in-situ high energy synchrotron tomography bending test, in submitted to Acta Materialia, 2015.

[24] M. Launey and R. Ritchie, Adv. Mater. 21, 2103 (2009).

[25] R. Ritchie, Mater. Sci. Eng. A 103, 15 (1988).

[26] ASTM E399-90, Standard Test Method for Plane-Strain Fracture Toughness of Metallic Materials, West Conshohocken, PA: ASTM International, Reapproved 1997.

[27] J. Murphy, et al., Journal of Nuclear Materials 386 - 388, 583 (2009).

[28] A. Manhard, Deuterium inventory in tungsten after plasma exposure: A microstructural survey, University of Augsburg, 2011, PhD Thesis.

[29] A. Manhard, et al., Prak. Metallogr. 50, 5 (2013).

[30] B. Tabernig and R. Pippan, Eng. Fract. Mech. 69, 899 (2002).

[31] D. Marshall, et al., Acta Metall. 33, 2013 (1985).

[32] M. Faleschini, et al., Journal of Nuclear Materials 367370, Part A, 800 (2007).

[33] A. Evans, J. Am. Ceram. Soc. 73,187 (1990).

[34] W. Eckstein and W. Möller, Nuclear Instruments and Methods in Physics Research Section B: Beam Interactions with Materials and Atoms 7, 727 (1985).

[35] T. Wegener, et al., New smart self-passivating tungsten alloys for future fusion reactors, in presented at the 15th Int. Conf. on Plasma-Facing Materials and Components for Fusion Applications (PFMC15), Aix-en-Provence, France, 2015.

[36] A. Calvo, et al., presented at the 15th PFMC workshop, accepted for publication in Physica Scripta (2015).

[37] H. Greuner, et al., Journal of Nuclear Materials 367370, Part B, 1444 (2007). 
[38] F. Koch, et al., Investigations on the Technical Production of Self-Passivating Tungsten Alloys, presented at the 17th International Conference on Fusion Reactor Materials (ICFRM-17), Aachen, Germany, 2015.

[39] J. Riesch, et al., Chemical deposited tungsten fibre-reinforced tungsten - The way to a mock-up for divertor application, presented at the 17th International Conference on Fusion Reactor Materials (ICFRM-17), Aachen, Germany, submitted to Nuclear Materials and Energy, 2015.

[40] B. Jasper, et al., Materials Science Forum 825-826, 125 (2015). 